ALTERIDADES, 2018, 28 (55): Págs. 75-85

https:www.doi.org/10.24275/uam/izt/dcsh/alteridades / 2018v28n55/Lozano

\title{
La lucha por el agua y la generación de un nuevo tipo de panindianismo*
}

LUZ LOZANO NATHAL**

\begin{abstract}
Fighting for Water and the Generation of a New Type of PAN-INDIANISM. In an era of globalization, it is clear an increase in Indian movements that intend to defend their native territory, and protect their natural resources such as water. Their demands are becoming more widespread as a result of the neoliberal economy and an accelerated extractive activity. This article considers historical examples of Pan-indian organizations which are directly related to recent events concerning the defense of the Missouri River, driven by the Lakota people, in the United States, during the past few years, and have become more important since Donald Trump assumed the presidency.
\end{abstract}

Key words: Lakota people, Standing Rock, Keystone XL

\begin{abstract}
Resumen
En tiempos de globalización, es patente el incremento de movimientos indios que tienen por objeto la defensa del territorio nativo y la protección de recursos como el agua, cuyas demandas se han generalizado a raíz de la economía neoliberal y la acelerada actividad extractiva. Este artículo aborda ejemplos históricos de organización panindia directamente relacionados con acontecimientos recientes en torno a la defensa del río Missouri, impulsados por la nación lakota en Estados Unidos durante los últimos años, que han cobrado relevancia a partir de la presidencia de Donald Trump. Palabras clave: nación lakota, Standing Rock, Keystone $X L$
\end{abstract}

$\mathrm{E}$ n la actualidad se han incrementado las denuncias contra las políticas neoliberales desde los pueblos indígenas en cuanto a la explotación forestal, la tala devastadora, los desvíos de aguas o su contaminación, la extractividad minera y petrolera en todas sus modalidades, la biopiratería, los asesinatos y amenazas a líderes ambientalistas indígenas, entre otras circunstancias, todas relacionadas con sus territorios y su identidad. Tales demandas se expresan también a través de las redes sociales, en una suerte de "activismo transnacional", como señala Escobar (1999: 373), ligado a las formas de lucha y circunstancias locales y que ha establecido lazos de solidaridad que a la larga pueden convertirse en los inicios de un nuevo tipo de alianzas panindias.

El objetivo de este artículo es dar un recuento general de un movimiento político panindio reciente en Estados Unidos, en particular de un movimiento contemporáneo que plantea la vigencia de las demandas históricas de los indígenas norteamericanos y sus territorios a partir de una posición ontológica y que se contrapone al que alude a la dualidad naturaleza-cultura y subraya en los hechos el carácter de mercancía de la primera. Se presenta el caso reciente de la lucha por el agua en la reserva de Standing Rock, Dakota del Norte.

\footnotetext{
* Articulo recibido el $02 / 05 / 17$ y aceptado el 27/07/17.

** Doctorante de la Escuela Nacional de Antropología e Historia. Periférico Sur y Zapote s/n, col. Isidro Fabela, del. Tlalpan, 14030, Ciudad de México.
} 
Atendiendo a la pertinente propuesta teórica desde la ecología política que busca articular los procesos históricos con los ambientales y la mediación cultural que establece esas relaciones (Escobar, 1999: 280), se hará una breve pero necesaria mención histórica sobre la confluencia de nativos americanos en los movimientos panindios que les dieron visibilidad e interlocución a sus demandas en diferentes momentos del siglo xx. Después, a partir de información obtenida a través de las redes sociales, ${ }^{1}$ y con base en un discurso que muestra una manera particular de concebir la relación con todo lo existente, se describe como antecedente inmediato el movimiento No Más Pasividad (Idle No More) -también vinculado con el agua- en Canadá, y, finalmente, se ofrece un panorama del movimiento No al Acceso al Oleoducto en Dakota (No Dakota Access Pipeline-NoDAPL-), surgido en Standing Rock.

\section{$* * *$}

En Estados Unidos, las alianzas tribales que permitieron adquirir visibilidad ante la sociedad dominante, así como una mayor capacidad de negociación con el Estado, han sido consideradas en general como movimientos panindianistas ${ }^{2}$ de carácter reformista (Hertzberg, 1981). Mientras que en el siglo XIX predominaron los movimientos panindios de corte milenarista, en el siglo posterior prevaleció la formación de organizaciones políticas con integrantes de diversas procedencias tribales. Varios factores contribuyeron a este fenómeno: las repercusiones de la aplicación de la Ley de Lotificación General, aprobada en $1887,{ }^{3}$ que modificó la relación del indio con su territorio; las escuelas de internados que favorecieron la formación de profesionistas indios, y el surgimiento de núcleos solidarios entre los miles de indios desplazados a las ciudades. Cuestiones como la "cantidad de sangre india", la identificación de rasgos comunes entre las tribus, el deseo de conservar expresiones rituales como las danzas y cantos, la posibilidad de aceptar la ciudadanía americana y, sobre todo, el común denominador del despojo de las tierras y los tratados no respetados, eran temas centrales de una polémica que impulsaba a las organizaciones a definirse como nativos americanos, a fin de incidir en las políticas indigenistas para defender sus territorios, recursos y formas de vida.

Existen varios ejemplos de esas organizaciones panindias de corte político. La primera fue la Sociedad de Indios Americanos, creada en 1910, con una fuerte tendencia hacia el asimilacionismo. Tuvo gran influencia del antropólogo Arthur C. Parker, nativo séneca, y del sioux Charles Eastman. Una década después de la aprobación de la Ley de Reorganización India en $1934,{ }^{4}$ impulsada por John Collier, se fundó el Congreso Nacional de Indios Americanos que usaba términos como pueblo indio, indio americano o simplemente indio para hablar de la identidad e intereses comunes, sin diluir las diferencias tribales (Hanson, 1997: 200; Hertzberg, 1981: 291). En su plataforma política manifestaba el compromiso con la soberanía tribal y la promoción del desarrollo de los recursos humanos y naturales en las reservas (Hanson, 1997: 200).

En la década de 1950, el gobierno de Estados Unidos siguió una política de terminación de los nativos americanos, desplazando a decenas de miles desde las reservas hacia las grandes ciudades, en un intento de asimilarlos al tejido social, "terminando", por ende, con las asociaciones tribales. ${ }^{5}$ La pregunta que varios antropólogos se hacían era por qué, a pesar de tantos esfuerzos gubernamentales, no se había logrado la total

1 La información pudo ser corroborada en pláticas informales en distintas etapas de los movimientos con Gilbert Running, miembro de la nación lakota en Iron Hill Top, reserva de Rosebud, Dakota del Sur, Estados Unidos, y Duane Good Striker, embajador de Asuntos Ambientales desde 2000, nación blackfoot, Edmonton, Canadá.

2 El término "panindianismo" fue acuñado en 1948 por Karl Schmitt, de la Universidad de Oklahoma, para describir el fenómeno social que estaba empezando a ocurrir a finales del siglo xix, cuando los omaha, los sioux y otras tribus nativas americanas empezaron a tener mayor contacto entre ellas (Belle, 2004: 26). En este escrito lo entendemos como el fenómeno de reunión, alianza y organización de dos o más pueblos indios en aras de objetivos comunes.

3 La Ley de Lotificación General (conocida también como Acta Dawes) obligaba a los indios a convertirse en "jefes de familia" y propietarios de parcelas con superficie acotada, afectando la noción comunal de la tierra. El gobierno retuvo grandes extensiones como depósito durante 25 años que nunca regresarían a manos indias (Zinn, 2010: 99).

4 Conocida también como Nuevo Tratado Indio o Acta Howard-Wheeler (Wilson, 1999: 178), esta Ley de Reorganización promovió la creación de una democracia representativa en los gobiernos de las reservas indias que ayudara a las tribus a: salir de la pobreza, ser autosuficientes, tomar el control de sus propios asuntos, formar constituciones tribales teniendo como modelo la Constitución de Estados Unidos; todo siempre con la supervisión y asesoría de la Oficina de Asuntos Indígenas.

5 En 1953, el Congreso aprobó la Resolución Simultánea-Concurrent Resolution- 108 (HCR 108), que inauguraba la política de terminación, y anunciaba el fin del reconocimiento federal de las tribus flathead, klamath, menominee, potawatomi y los chippewa de Turtle Mountain. En 1956 se reubicó a miles de indios desde las reservas hacia remotos centros urbanos (Estes, 2016). 
asimilación del indio (Hertzberg, 1981: 156). Robert K. Thomas (1965: 81) afirmó que era precisamente ese desplazamiento a las ciudades y la formación de una comunidad panindia lo que favorecía el resurgimiento de una identidad tribal, aun cuando preveía que esas comunidades "indias" urbanas podrían ser sólo estancias temporales para los individuos indios que más tarde se incorporarían a la clase media nacional.

En las ciudades, en efecto, muchos miembros de las sociedades tribales desarrollaron una nueva conciencia de ser indio, de manera que durante la década de 1960 floreció un panindianismo de tinte político. A los movimientos y organizaciones contra la política racista (como Black Power y Chicano Power) se incorporó un nuevo movimiento indio que erigió un discurso redoblado sobre la soberanía de las tribus, el respeto a sus derechos y el reforzamiento de la relación con la reserva; ahora, "ir de regreso a la frazada" -back to the blanket, un término que se refería a "volver a caer en la cultura tribal tradicional" (Hanson, 1997: 196)- tenía más connotaciones positivas que negativas. Surgieron así dos nuevas organizaciones indias urbanas, ambas orientadas hacia la difusión de sus demandas en los medios de comunicación y con estrategias de confrontación.

Una de ellas fue el Consejo Nacional de la Juventud India, creado en junio de 1961 como resultado de la Conferencia del Indio Americano organizada por la Universidad de Chicago, con el activo liderazgo de Sol Tax. ${ }^{6}$ Entre los postulados del Consejo se contemplaba la oposición a la exterminación del indio, el reconocimiento a la soberanía inherente de las tribus, así como el énfasis en la perpetuación de la cultura india, la autodeterminación y la defensa activa del ejercicio de sus derechos. El movimiento proponía el uso de la acción directa y no violenta para atacar la segregación y otras formas de racismo (Heppler, 2009: 32). La otra organización fue el Movimiento Indio Americano, fundado en 1968. Su plataforma se centraba en la autodeterminación, la soberanía tribal, los derechos legales y el mejoramiento del currículo de la escuela pública sobre la historia de los indios americanos. Sus estrategias incluyeron la protesta pública, la toma de instalaciones y la captación de la atención de los medios impresos y la televisión (Hanson, 1997: 202).
Una acción conjunta entre el Consejo, el Movimiento Indio y otras organizaciones más pequeñas, todas bajo la bandera del Poder Rojo, fue la toma de la isla de Alcatraz, en la bahía de San Francisco, ya abandonada después de fungir como prisión federal. Justificándose en una cláusula del Tratado de Fort Laramie de 1868 , con ese acto se reclamaba esa tierra como suya por "derecho de descubrimiento", para convertirla en un Centro Cultural Nativo Americano (Heppler, 2009: 33). Durante los 19 meses que duró la ocupación, los medios de comunicación destacaron a los jóvenes que habían dejado el saco y la corbata y ahora en su discurso promovían el nacionalismo panindio, denunciaban los múltiples tratados rotos y levantaban sus demandas políticas junto a la recreación de mitos nativos americanos; asimismo, ostentaban sus largas cabelleras, enarbolaban símbolos como el tipi y la pipa, hacían cantos y danzas nativos, sus atuendos en mucho remitían al estereotipo del indio de las planicies como una impactante imagen que englobaba la indianidad compartida. Su amplia difusión en los medios logró la simpatía del público estadounidense.

El Movimiento Indio Americano tuvo otro momento de impacto mediático con la ocupación de Wounded Knee, en 1972-1973, un sitio emblemático de la reserva lakota de Pine Ridge, en Dakota del Sur. ${ }^{7}$ Más de 200 hombres y mujeres lakota oglala ocuparon esa comunidad en contra de las acciones persecutorias y represivas de los empleados de la Oficina de Asuntos Indios y con las demandas inmediatas del cambio de los jefes de la tribu, la investigación de los tratados con el gobierno federal y la rectificación del trato recibido por los indios (Rios, 2008: 52; Ortega, 1992: 35). En respuesta, el gobierno ordenó sitiar el lugar y mantener una estrecha vigilancia sobre los participantes. Después de 71 días de ocupación, se produjo el desalojo que dejó tres indios muertos y más de 300 detenidos (Heppler, 2009: 71). Luego de este enfrentamiento y durante décadas, el movimiento panindio en Estados Unidos ya no partió de organizaciones nacionales de carácter intertribal, sino que continuó con movimientos locales, sobre todo en torno al rechazo de la disminución progresiva de los territorios de las reservas y al logro de derechos como la salud y la educación.

6 Recordemos que durante varios años Sol Tax estuvo trabajando junto a Robert Redfield con grupos mayas en Guatemala y México. Fue profesor visitante de 1942 a 1943 en la Escuela Nacional de Antropología e Historia. Trabajó junto con el antropólogo mexicano Alfonso Villa Rojas entrenando a estudiantes y con jóvenes antropólogos en las comunidades tzeltal y tzotzil de Chiapas, como director del programa El Hombre en la Naturaleza, en el proyecto de la Universidad de Chicago en ese estado.

7 En diciembre de 1890, Wounded Knee fue escenario de una de las masacres más cruentas e inexplicables del ejército estadounidense contra la población lakota. 


\section{No Más Pasividad}

De manera global, los actuales movimientos indios continúan levantando sus demandas por la conservación de sus territorios y en repudio a las políticas neoliberales que promueven un fuerte extractivismo de sus recursos. En estrecha relación con los nativos americanos, uno de estos casos es el movimiento en la provincia de Saskatchewan, Canadá, iniciado cuando se dio a conocer un conservador proyecto que transformaba la Ley de Protección de Aguas Navegables, vigente desde 1882, en una nueva ley llamada, simplemente, Ley de Protección de Navegación, la cual abría la posibilidad de atravesar los ríos y áreas de ecosistemas cruciales -la mayoría de ellos en territorio de las primeras naciones de Canadá- a favor del desarrollo industrial, en especial para proyectos destinados al paso de redes de oleoductos, con objeto de conducir el petróleo de las reservas canadienses hacia refinerías de Estados Unidos. La nueva ley no proveía garantía alguna de que no se dañarían las aguas navegables que atravesaran (Tupper, 2014: 91). Entonces nació el movimiento No Más Pasividad (Idle No More), tanto de entre los pueblos aborígenes ${ }^{8}$ como de los no indios. La campaña tomó fuerza en diciembre de 2012 desde la visión de la unidad para una revolución pacífica; un desarrollo saludable, justo, equitativo y sustentable; honrar la soberanía indígena, y proteger la tierra y el agua. ${ }^{9}$

Las acciones de No Más Pasividad se intensificaron a principios de 2013: pláticas, mítines, flash mobs -“intervenciones rápidas"- con la ejecución de danzas y cantos en los centros comerciales, y la toma de vías del tren, como la realizada entre Toronto y Montreal (Tupper, 2014: 91). Pronto las acciones de apoyo y las expresiones de solidaridad provinieron de otras ciudades de Canadá, pero también llegaron de Suecia, Inglaterra, Alemania, Austria, Nueva Zelanda y Egipto. En la Unión Americana hubo muestras solidarias en estados como Michigan, Minnesota, Ohio, Nueva York,
Arizona, Vermont, Carolina del Sur, Washington, Indiana y Texas. No Más Pasividad también correspondió con declaraciones de apoyo a otros movimientos, entre ellas las dirigidas, en junio de 2015, a las familias de los 43 estudiantes desaparecidos en Ayotzinapa, México; o bien, hacia los chippewas de la Primera Nación de los Thames ${ }^{10}$ en su lucha contra un proyecto de oleoducto en su territorio.

Así como el caballo y el ferrocarril en el siglo xIx, o la prensa y la televisión en la segunda mitad del xx, las redes sociales fueron definitivas en el establecimiento de la solidaridad panindia y su difusión; mediante ellas, No Más Pasividad creó lazos entre las primeras naciones con otros indios, con los movimientos ambientalistas y con simpatizantes en general, a través de su sitio electrónico \#IdleNoMore, que se extendió a otras redes como Twitter y Facebook. ${ }^{11} \mathrm{El}$ manifiesto del movimiento y los artículos de reflexión sobre la situación de los indios en Canadá empezaron a llamar la atención y a difundirse con rapidez. Los videos circulantes en redes mostraban la centralidad de personajes de las primeras naciones en las marchas, mítines, danzas, cantos y testimonios, dando el sello de identidad panindia al movimiento, sin dejar de verse el apoyo y participación de grupos ambientalistas no indios y de otros sectores de la ciudadanía canadiense. La aprobación o suspensión de la Ley de Protección de Navegación sigue pendiente.

\section{No al Acceso al Oleoducto en Dakota}

Después de décadas de movimientos de baja frecuencia e intensidad, No Más Pasividad fue el antecedente inmediato de un movimiento nativo americano sin precedente en Estados Unidos. Lo promovió el Consejo de los Siete Fuegos -Oceti Sakowin-, una histórica coalición de tribus de la familia lingüística siouana, que agrupa tres divisiones dialectales: santee, yankton y teton o lakota, que a su vez se subdividen en siete

8 Canadá considera como pueblos aborígenes a: 1) las primeras naciones (por ejemplo, los Musqueam Indian Band, los Sturgeon Lake First Nation y los atikamekw de Manawan; 2) los métis, cuyo origen se remonta al siglo xviII como resultado de matrimonios entre franceses y escoceses con mujeres aborígenes como las cree o las anishinabe (ojibwas), y fueron reconocidos como pueblo aborigen en 1982; y 3) los inuit, que se extienden desde la Península de Labrador hasta territorios del noroeste de Canadá. Véase: http:/ / www12.statcan.gc.ca/nhs-enm/2011/as-sa/99-011-x/99-011-x2011001-eng.pdf

9 Véase http: / / www.idlenomore.ca/

${ }^{10}$ Los chippewas se llaman a sí mismos anishinabek y se conocen también como ojibways. Habitan en el lado norte del río Támesis, aproximadamente a $20 \mathrm{~km}$ de London, Ontario, Canadá. Véase http://www.cottfn.com/

${ }^{11}$ Señala Jennifer Tupper (2014: 91): "el uso del hashtag en Twitter, \#IdleNoMore, facilitó la difusión de información y la organización de varios eventos y acciones, y llegó a ser tendencia. Ese hashtag tuvo hasta 21700 seguidores y generó 5000 tweets sobre asuntos aborígenes de Canadá. De igual manera, el movimiento tuvo una presencia en Facebook, con más de 127000 'me gusta' desde que la página www.facebook.com/IdleNoMoreCommunity fue creada y dio a conocer nuevos artículos sobre eventos organizados por el movimiento para aprender sobre él y apoyarlo, especialmente las críticas a la política del gobierno y los procesos y experiencias del colonialismo". 


\section{Figura 1 \\ Distribución geográfica \\ del Consejo de los Siete Fuegos (Oceti Salcowin)}

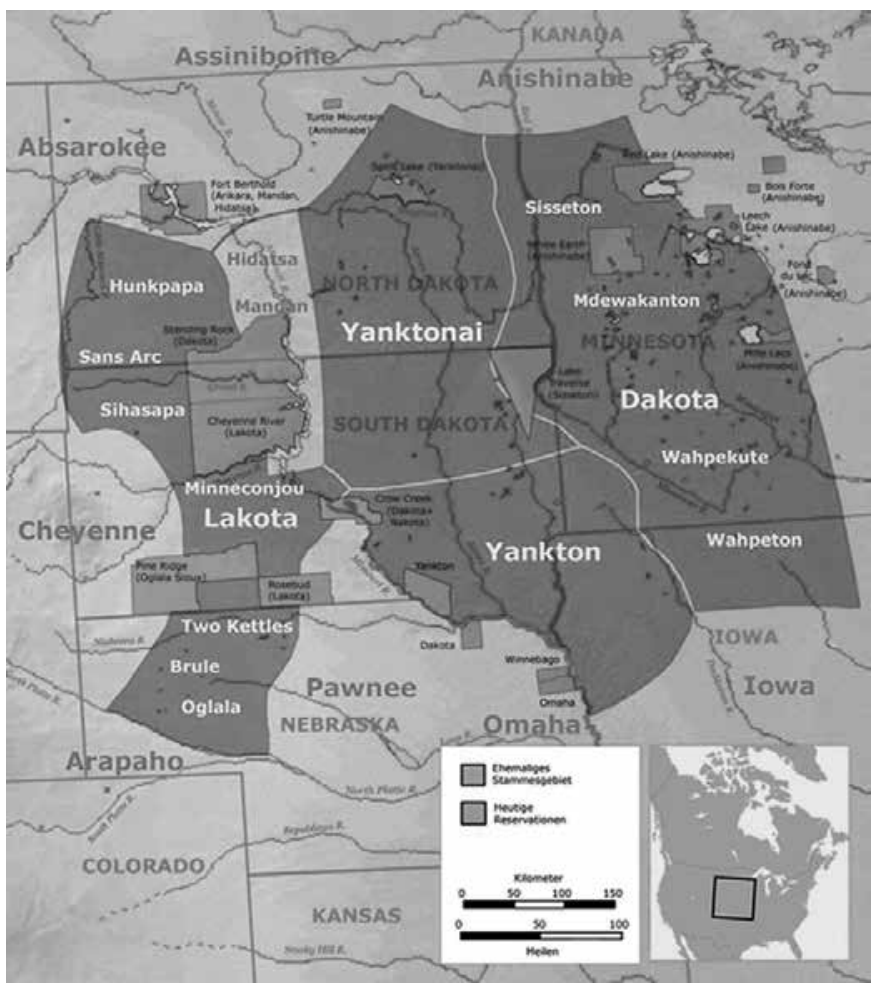

Fuente: http: / www.warpaths2peacepipes.com/nativeamerican-indians/sioux-land.htm [12 de mayo de 2013].

grupos, conocidos genéricamente como sioux, ${ }^{12}$ y que ocupan el norte de la región de las Grandes Planicies.

En 2016, los habitantes de la reserva lakota de Standing Rock convocaron al Consejo de los Siete Fuegos para emprender el movimiento No al Acceso al Oleoducto en Dakota (No Dakota Access Pipeline -NoDAPL-). Un par de años antes, el Consejo había iniciado la organización en contra del oleoducto Keystone XL que amenazaba con cruzar el río Missouri y que forma parte de una serie proyectos de la empresa TransCanada ${ }^{13}$ para transportar petróleo de arenas bituminosas y petróleo de esquisto desde la provincia canadiense de Alberta hasta Steele City, en Nebraska, y de ahí distribuirlo por diferentes rutas a refinerías en Texas, Estados Unidos. La compañía texana Energy Transfer Partners es la encargada de construirlo a través de casi dos mil kilómetros, con un costo de 3.8 billones de dólares, para conducir 570 mil barriles de petróleo por día. En un momento dado, un considerable tramo del proyecto cambió su ruta para evitar pasar

\section{Figura 2 \\ Proyectos de oleoductos de la compañía TransCanada}

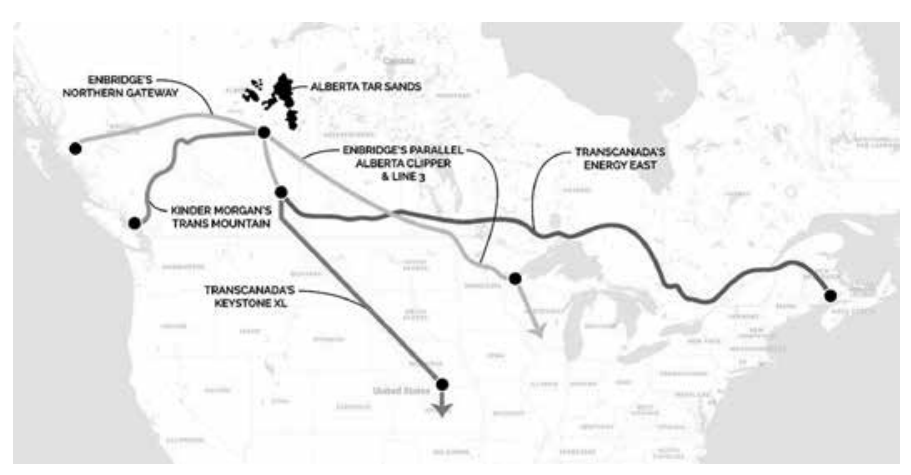

Fuente: http: / / earthfirstjournal.org/newswire/2016/09/23/ first-nations-and-tribes-sign-new-treaty-joining-forces-tostop-all-tar-sands-pipelines /

por poblaciones de mayoría blanca y fue desviada de tal modo que en Dakota del Norte cruzaría por debajo del río Missouri, a poco más de 1.5 kilómetros río arriba de la reserva lakota de Standing Rock.

Además de significar un potencial riesgo de derrame que contaminaría las aguas del río Missouri, del que dependen ocho mil miembros tribales y, en su curso subsecuente, casi 17 millones de americanos, también se atentaba contra sitios sagrados y cementerios. El movimiento que generó este oleoducto tiene que ver con la larga historia de los tratados no cumplidos de los que han sido objeto los nativos americanos y que están dirigidos a disminuir sus territorios y anular los derechos sobre el agua.

Los argumentos históricos y centrales en cuanto al territorio y al uso del agua que levanta el Oceti Sakowin se basan en los tratados de Fort Laramie de 1854 y 1868, establecidos entre el gobierno y las diferentes tribus sioux, que definían un vasto territorio de $25 \mathrm{mi}$ llones de acres que se convertirían en la Gran Reserva Sioux, desde la ribera este del río Missouri hasta las montañas Big Horn. Después de cuatro décadas, el territorio se vio disminuido con la Ley de Apropiación de 1876, que abolió los tratados hechos con las naciones nativas, y con la Ley Black Hills de 1877, en la que ilegalmente se les hizo ceder las tierras de Black Hills (al oeste de la Gran Reserva) para transformarlas en área de Reserva Natural, quedando, por tanto, a cargo del gobierno federal. El Oceti Sakowin nunca reconoció estas leyes (Estes, 2016). Por otra parte, en 1908, una decisión de la Corte Suprema de Estados

\footnotetext{
${ }^{12}$ El término sioux suplantó a la autodenominación original de estas tribus: Oceti Sakowin, el Consejo de los Siete Fuegos o Los Siete Lugares de Fuego.

${ }^{13}$ Los otros proyectos de oleoductos son Kinder Morgan, Energy East, Line 3 y Northern Gateway.
} 
Unidos afirmó que las tribus mantendrían el acceso y control del agua dentro del territorio original, incluso si éste hubiera disminuido, como en el caso sioux. Esto se conoció como la Doctrina Winters. ${ }^{14}$

\section{Figura 3 \\ Trayecto del oleoducto en la reserva de Standing Rock}

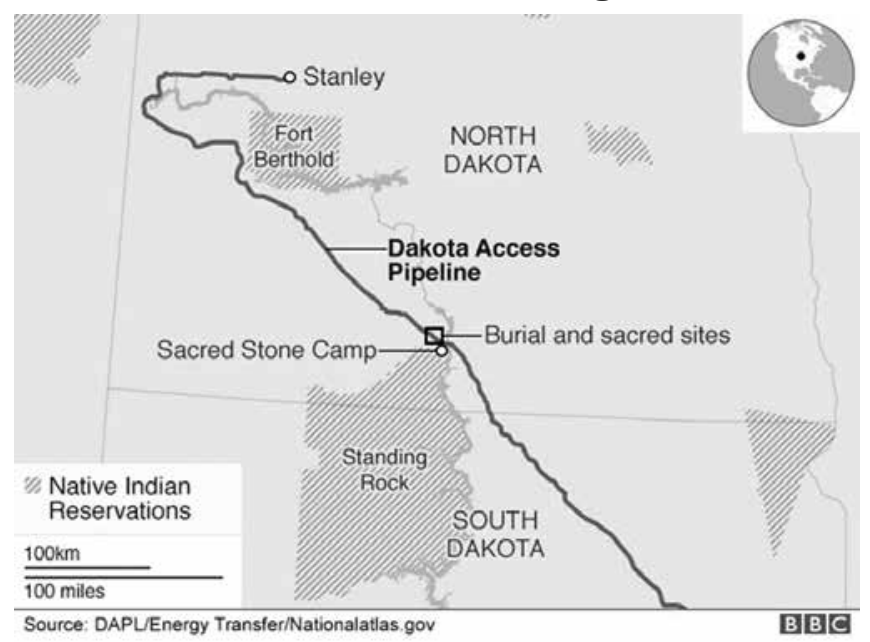

Fuente: https: / /www.tekcrispy.com/2017/02/10/sereinicia-la-construccion-del-oleoducto-dakota-access / dakota-access-pipeline/

Desde 1876, con la victoria tribal conjunta sobre el ejército estadounidense en la batalla de Little Big Horn, el Consejo de los Siete Fuegos no se había reunido tan firmemente como ahora en defensa de las aguas del río Missouri y en protesta contra el oleoducto. Se decidió emprender una acción coordinada: la instalación de una serie de campamentos en las cercanías del río Missouri, en la reserva de Standing Rock, nombrándolos Oceti Sakowin, Sacred Stone y Red Warrior.

Es así como inicia de lleno el movimiento NoDAPL. Su demanda principal de defensa del agua se resume en la frase lakota Mni Wiconi -el agua es vida- y declaró a sus integrantes como "Protectores del agua" -"We're no protesters, We're protectors"-. Aunque para muchos el movimiento evocaba cierto sabor a la toma de Wounded Knee de 1973, en Standing Rock quedó claro desde el inicio que su resistencia se haría con acciones directas y no violentas, acciones de paz y rezo, ${ }^{15}$ lo que contó para atraer la solidaridad de comunidades indias y no indias. Su estrategia se basó sobre todo en el principio ontológico animista de que la tierra, el agua, las plantas, los animales, son seres vivos y con espíritu, por tanto, no se trata de "recursos" sino de entidades que los relacionan como parientes y, como tales, han de cuidarse y procurarse mutuamente en armonía y equilibrio, siguiendo las enseñanzas de sus antepasados. ${ }^{16}$

\section{Convocatoria y solidaridad}

De la primavera al verano de 2016 , los campamentos se fueron nutriendo; llegó gente no sólo de las naciones lakota, dakota y nakota sino de todas las Grandes Planicies y de cientos de naciones tribales de Estados Unidos. Se levantaron tipis y áreas para tiendas de campaña y campers, se destinaron otras para danzas y cantos, cocinas comunitarias, espacios para talleres y pláticas, zonas de resguardo para caballos. En el campamento Oceti Sakowin se izaron más de 200 banderas tribales. Para agosto, ya habían llegado diez mil personas, provenientes de Guatemala, Honduras, Perú, Colombia, Canadá, México, Noruega, República Checa, Sudáfrica y Filipinas. El movimiento se apoyaba en la unidad multinacional nativa y no nativa (Argentina Indymedia, 2016).

Bajo el lema "Estoy con Standing Rock"-I Stand with Standing Rock- se recibió la solidaridad de integrantes de movimientos como Black Lives Matter (La Vida de los Negros Importa) y el grupo de danza azteca de Minessota Kalpulli Yaocenoxtli. Se enviaron mensajes desde Estonia y el pueblo sami de Noruega. Fueron visitados por el pueblo kichwa de Sarayaku, de la amazonia ecuatoriana. De México, destacó la presencia de Mario Luna, vocero tradicional de la tribu yaqui de Sonora, con el testimonio de su lucha en contra del Acueducto Independencia que desvía el agua del río

${ }^{14}$ La Doctrina sobre Derechos Reservados al Agua o Doctrina Winters garantizó a las tribus el derecho para valerse del agua y así cubrir los requerimientos de las reservas. El derecho podía ser ejercido en cualquier momento en el futuro, incluso si los individuos no indígenas se hubieran valido del agua con anterioridad y se les hubieran otorgado derechos bajo la ley estatal (Getches, 2002: 17). Esta ley pretendía que la cercanía con el agua les permitiera tanto la sobrevivencia como el recurso en labores de pesca y para los terrenos que cultivaran como granjeros individuales. Problemas sobre el agua y las naciones nativas abundan en todo el territorio estadounidense y se resuelven mediante negociación local, o bien, se llevan a litigio a las cortes estatales.

${ }^{15}$ En declaraciones reiteraban: "Oramos por el agua usada por agricultores en Iowa e Illinois, el agua consumida por niños de las escuelas en Dakota del Sur, Missouri, Tennessee y Arkansas".

${ }^{16}$ Al respecto, hay que recordar a Descola y su caracterización de un pensamiento ontológico animista que en su inventario de existentes incorpora a los no humanos, en cuanto a que las sociedades de la naturaleza no separan a los humanos de los animales, las plantas, los espíritus, los muertos, los fenómenos meteorológicos, entre otros, porque están dotados de conciencia, es decir, de lenguaje, razón, intelecto y código moral (Descola y Palsson, 2001: 18). 
Yaqui para llevarla a la ciudad de Hermosillo, coincidiendo con la demanda de Standing Rock (Argentina Indymedia, 2016; Sacred Stone Camp, 2016).

Las identidades estaban bien definidas, no se habló de un "indio" que representara a todos los nativos, de hecho, se establecieron las diferencias tribales y su unidad en contra de los oleoductos y por la defensa del agua en sus respectivos lugares. Causó gran impacto que en septiembre se reunieran en el tipi principal docenas de líderes de distintas tribus nativas americanas en un acto ceremonial de solidaridad. También, que una delegación de la nación crow, enemiga de los sioux por más de un siglo, llegara desde Montana con ofrendas para el fuego y con $300 \mathrm{~kg}$ de carne de búfalo para el campamento, como gesto de solidaridad y amistad (Woolf, 2016).

NoDAPL tuvo acciones paralelas a la instalación de campamentos. A principios de septiembre de 2016 se expusieron ante la Corte Federal los archivos tribales que documentan que una porción de la ruta propuesta en el proyecto del oleoducto atraviesa múltiples cementerios y sitios sagrados. ${ }^{17}$ Ese mismo mes, el jefe sioux de Standing Rock, David Archambault II, se presentó ante el Consejo de Derechos Humanos de la Organización de las Naciones Unidas (onu) y dijo que las cortes estadounidenses habían fallado en proteger los derechos soberanos de los pueblos nativos, pidió que los estados miembros de la onu condenaran la destrucción de su tierra sagrada y subrayó el papel clave de la cultura indígena en la preservación de la naturaleza y el ambiente: "Nosotros protegemos a todos los parientes que tenemos y esos parientes son las plantas, los animales, el agua. Lo que pensamos de ellos es que son seres reales que son preciados para nosotros, y son los pueblos indígenas los que comparten eso" (Native Daily Network, 2016). ${ }^{18}$ En un foro realizado por House Democrats en Washington, D. C., explicó sobre la cosmología lakota:

Estamos ligados con el Universo... todos nuestros espíritus están conectados con el Universo... Nuestros antiguos cementerios, los lugares donde descansan nuestros ancestros lakota y dakota, han sido destruidos. Imaginen una máquina excavadora entrando al cementerio de sus familias: es inimaginable. Es lo que la empresa petrolera ha permitido (Braine, 2016).

Las primeras naciones canadienses y los jefes tribales se reunieron en el museo Muequeam de Vancouver y en territorio Mohawk en Montreal para firmar el Tratado de Alianza contra la Expansión de Arenas Petrolíferas-Treaty Alliance Against Tar Sands Expansion-, que compromete alrededor de 50 primeras naciones y tribus de Canadá y del norte de Estados Unidos para trabajar unidas en detener todo proyecto de oleoducto y ferroviario. Uno de los dirigentes advirtió: "Estamos en un tiempo de unidad sin precedentes entre las naciones indígenas para luchar por un futuro mejor para cada una" (Earth First! Newswire, 2016).

El Museo Nacional de Historia publicó un documento con la firma de casi 1300 arqueólogos en el que llamó al gobierno federal a que hiciera más por proteger los sitios sagrados de la tribu (Braine, 2016). La American Anthropological Association se solidarizó públicamente con Standing Rock y denunció que el proyecto Keystone XL rompía con los tratados de Fort Laramie de 1851 y 1868, además de violar el Acta Nacional de Política Ambiental y el Acta Nacional de Preservación Histórica. También se expresaron en solidaridad la Iglesia Nativa Americana y varias iglesias cristianas: la Metodista Unida, la Unida en Cristo, la Episcopal, la Presbiteriana y la Evangélica Luterana. ${ }^{19}$

Hay que señalar dos momentos en México: en septiembre de 2016, mujeres de origen ñhañhú que integran el Consejo Xängü Yamui, defensoras de la sierra de Hidalgo y Puebla, rechazaban la construcción del gaseoducto Tuxpan -a cargo también de la empresa multinacional TransCanada y de su filial en México-, por considerar que con ello se destruiría más de 600 hectáreas de bosque y se pondría en riesgo la vida, el agua y la tierra en 130 comunidades originarias. Un movimiento relativamente circunscrito a lo local pero con las mismas demandas y contra la misma empresa (Llaven Anzures, 2016). El segundo momento fue el 21 de febrero de 2017, durante la Caravana por la $\mathrm{Paz}$ y la Vida, convocada por diversas organizaciones en lucha por la defensa de la tierra y el agua. Ahí estuvo la mujer lakota Cheryl Angel para manifestarles la

${ }_{17}$ Véase p. 3.11.9 del "Final Supplemental Environmental Impact Statement. Keystone XL Project”, donde ya se había asentado que en las reservas indias por las que atravesaría el proyecto Keystone XL existen sitios arqueológicos, cementerios y lugares de uso espiritual y tradicional <https://2012-keystonepipeline-xl.state.gov/documents/organization/221 158. pdf $>$.

18 Señala Arturo Escobar un aspecto ontológico: "cuando se habla de una montaña [en este caso, el agua del río Missouri] como un ancestro o como una entidad sintiente, se está haciendo referencia a una relación social, no a una relación de sujeto objeto. Así, el concepto de comunidad, en principio centrado en los humanos, se expande para incluir a no-humanos" (Escobar, 2014: 103).

${ }_{19}$ Véase https: / / www.ncronline.org/blogs/ncr-today/catholics-seem-absent-standing-rock-pipeline-protest 
solidaridad de Standing Rock y explicarles sus demandas en contra del Dakota Access Pipeline (Enciso, 2017).

En los campamentos de NoDAPL, los mitos, como en todo movimiento nativo americano, se hicieron presentes. Se mencionaron continuamente dos profecías: una atribuida al lakota Black Elk a fines del siglo xIx, sobre la esperanza del resurgimiento de su pueblo en las siete generaciones siguientes para salvar a la tierra -la actual sería esa séptima generación-. Otra, la de que "los ancestros ya decían que una serpiente negra-zuzeca sapa- se arrastraría por el mundo ensuciando el agua y causando gran destrucción a los habitantes de la tierra; habría que vencerla para sobrevivir" (Tolan, 2016); por supuesto, la serpiente negra se identificó con el oleoducto. Por otra parte, un momento que remitió al mito de la alianza entre la nación sioux y la nación búfalo ocurrió cuando la policía armada intimidaba a los protectores, y aparentemente de la nada se acercó a trote una manada de búfalos, ocasionando gran algarabía entre los activistas por lo inesperado y oportuno de su presencia, la que consideraron un refrendo a lo correcto de sus acciones (véase Protect Mother Earth, 2016).

En el auge del movimiento, la policía militarizada también hizo su trabajo con su constante e intimidante presencia, a la que los protectores respondían con acercamientos cara a cara para explicarles los motivos de sus acciones e incluso saludarlos de mano. El 3 de septiembre llegaron al lugar máquinas excavadoras a trabajar en una extensión de tres kilómetros para hacer acotamientos a lo largo de cada lado del río Missouri. La gente que trató de detener las labores fue agredida con gas pimienta y perros guardianes, resultando varios heridos, mordidos, afectados por el gas y más de 20 arrestos (Braine, 2016). La compañía Energy Transfer Partners amenazó con emprender acciones legales por considerar que los defensores del territorio amenazaban la seguridad energética de Estados Unidos. En octubre se arrestó a 141 activistas que habían movido sus tiendas y tipis hasta el punto de avance de la línea.

La acción más contundente de la policía fue la noche del domingo 20 de noviembre: alrededor de 400 activistas removieron una barricada de bloqueo puesta para proteger el área de construcción del oleoducto, argumentando que impedía los servicios de emergencia y que personas llegaran desde Standing Rock a los campamentos. La policía utilizó simultáneamente gas, balas de goma y cañones de agua (en un ambiente de $-5{ }^{\circ} \mathrm{C}$ ) para dispersarlos. Muchos salieron heridos $\mathrm{y}$ al menos 17 personas fueron llevadas al hospital para curar sus heridas o por presentar hipotermia (Hawkins, 2016).

Durante diciembre, llegaron en apoyo al campamento alrededor de dos mil veteranos militares de Estados Unidos. Decían estar dispuestos a exponer sus cuerpos entre los nativos y la policía militarizada por su experiencia de haber estado antes frente al fuego de las balas. Llegaron con una fuerte cantidad de dinero para ser usada en las necesidades del campamento (The Independent/UK, 2016).

Las redes sociales de comunicación muestran su efectividad en los movimientos ambientalistas al difundir paso a paso su proceso y suscitar la empatía y la respuesta solidaria, ejerciendo una ciberpolítica ambientalista que conecta lo local con lo global (Escobar, 1999: 355). La intensidad de NoDAPL no se explicaría sin la abundante generación de videos, muchos de ellos de excelente calidad, que dieron al movimiento una ventana hacia Estados Unidos y el mundo. En redes sociales -YouTube, Facebook, \#NoDAPL- se dio cuenta, muchas veces en tiempo real, del crecimiento de los campamentos, su organización, ceremonias y danzas; los ininterrumpidos trabajos en la línea de conducción del oleoducto por parte del Cuerpo de Ingenieros del Ejército; los discursos de los jefes de tribu (Archambaudt, Leonard Crow Dog, Arvol Looking Horse, entre otros), de exdirigentes del Movimiento Indio Americano como Dennis Banks, de artistas de cine como Mark Ruffalo, Jane Fonda o Leonardo DiCaprio; el arribo de cientos de distintos pueblos nativos -como la impresionante llegada en canoa de mujeres de la tribu colville, del estado de Washington-; la "visita" de los búfalos; las reflexiones de los activistas; los cantos de muchas partes del mundo en solidaridad con Standing Rock; los discursos que se decían a los policías militarizados; la súplica de perdón de los veteranos hacia los nativos americanos; la reactivación del discurso sobre derechos indígenas que en 1989 hiciera Russell Means (19332009), fundador del Movimiento Indio Americano; ${ }^{20} \mathrm{el}$ "Urgente llamado de las mujeres de Standing Rock", del 20 de febrero de $2017 ;{ }^{21}$ la desocupación del campamento y mucho más.

Fue novedoso el uso de drones que evidenciaban las tácticas de acercamiento de la policía armada al campamento, los momentos de represión como el del 20 de noviembre, los avances de la construcción del oleoducto, etcétera. Decía un operador de drones: "Estamos mandando señales digitales de humo

\footnotetext{
${ }^{20}$ Véase Mic, página de Facebook, con 3180643 reproducciones.

${ }^{21}$ Véase Shaun King, página de Facebook, con 677170 reproducciones.
} 
hacia todo el mundo". No expresaron un movimiento panindio en el sentido de defender una identidad india generalizada, sino en coincidir en la protección del agua: "Debemos enfocarnos en lo común, en lo que nos conecta a todos en el mundo. Y eso es el agua", declaraba uno de los integrantes del movimiento. El poder de convocatoria de la reserva lakota de Standing Rock, la cobertura de prensa y televisión, las miles de fotografías, entrevistas y reseñas en las redes sociales, y esas "señales de humo" convierten al NoDAPL en el movimiento nativo americano más difundido de toda la historia.

Un hecho alentador fue cuando Barak Obama, en diciembre y ya a punto de dejar la presidencia, ordenó la suspensión temporal de la construcción para que el Cuerpo de Ingenieros del Ejército hiciera una "consistente consideración y discusión de locaciones alternativas para que el oleoducto cruce el Río Missouri" (Simon y Weinsten, 2017), cuestión que podía tardar años.

\section{El fin del campamento}

Poco después del memorándum presidencial, el gobernador de Dakota del Norte, Doug Burgum, ordenó la evacuación de los campamentos para que los activistas no se vieran afectados por las inundaciones derivadas de la construcción del oleoducto (Enciso, 2017). La fecha límite para la desocupación se fijó para el miércoles 22 de febrero de 2017. Aunque la tribu de Standing Rock había desafiado la decisión de Donald Trump en la corte, el Consejo Tribal consideró pertinente el cierre de los campamentos para evitar enfrentamientos (Wong, 2017). Después de semanas invernales de relativo "silencio" en la campaña de NoDAPL, la gente empezó a abandonar el campamento con enojo y tristeza, pero con la determinación de seguir con el movimiento: "El cierre del campamento no es el fin, es un nuevo comienzo. El fuego que inició Standing Rock, está prendido en cada uno de nosotros", dijo Tom Goldtooth, presidente ejecutivo de la Red Ambiental Indígena (Wong, 2017). NoDAPL tuvo cierta reanimación al instalar, del 7 al 10 de marzo de 2017, un campamento en Washington, D. C., con la demanda de defender el agua del río Missouri, sin embargo, en los meses subsecuentes, su intensidad disminuyó. Se sabe que de las 761 personas arrestadas durante el movimiento, para julio se habían resuelto tan sólo 114 casos gracias a un equipo de asesores legales que atiende a los Protectores del Agua.

Habría otra cuestión que enfrentar. Apenas a cuatro días de haber tomado la presidencia, Trump firmó el 24 de enero de 2017 una orden ejecutiva para reanudar el proyecto Keystone XL e instruyó al Cuerpo de Ingenieros del Ejército que "revisara y aprobara" el oleoducto de una manera expedita "al alcance permitido por la ley" (Simon y Weinsten, 2017). Debe señalarse que Trump vendió en diciembre de 2016 las acciones que tenía en Energy Transfer Partners, previendo un conflicto de intereses; además se hizo público que el dueño de esa compañía había donado 100 mil dólares a la captación de fondos del Partido Republicano para la campaña de Trump (McBride, 2017).

Trump apostó por el desarrollo de las industrias del petróleo y del carbón. Finalmente, el 25 de marzo de 2017, el Departamento de Estado anunció la aprobación de la construcción del oleoducto Keystone XL, "como parte de una nueva era de la política energética estadounidense", dijo el presidente, en la que se reducirán los costos y la dependencia del petróleo extranjero, y se crearán 100 mil empleos "americanos" (La Jornada, 2017). Coherente con su política racista y discriminatoria, ${ }^{22}$ ninguna referencia fue hecha a

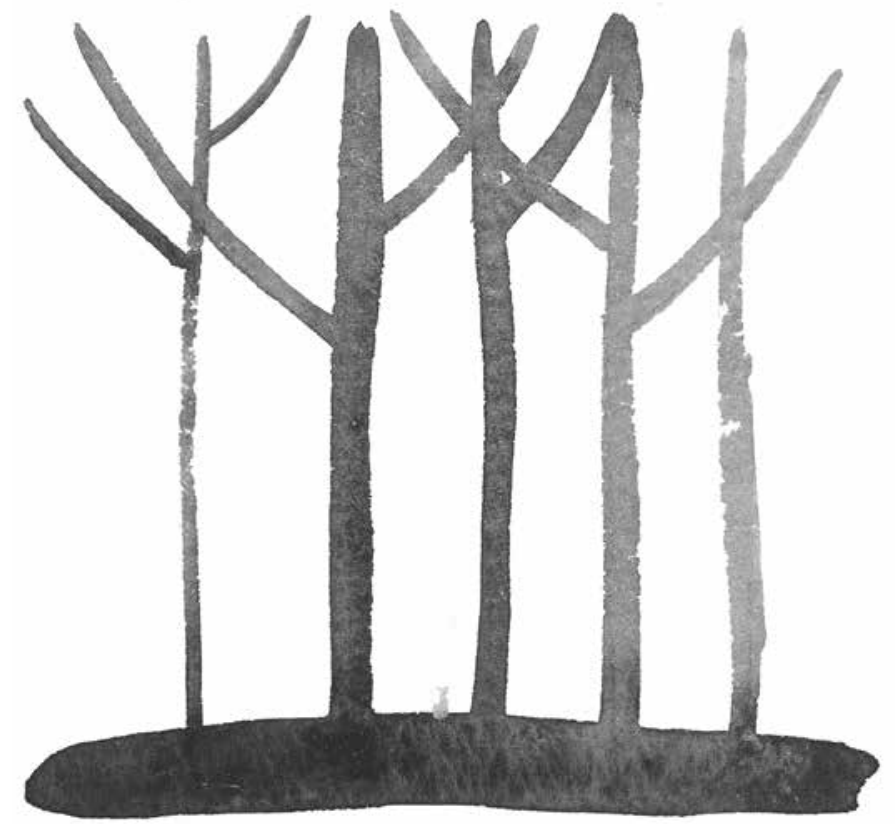

${ }^{22}$ Donald Trump ha declarado que su contraparte histórica es Andrew Jackson, presidente de Estados Unidos (1829-1837), un comerciante defensor de la esclavitud y promotor de lo que se conoce como la "remoción indígena" y que legalizó el agresivo, forzado e inclemente desplazamiento de tribus hacia el oeste del río Mississipi, liberando el lado este para la voraz compra de tierras por pudientes estadounidenses. Con igual egomanía de quien lo ha escogido como fuente histórica inspiradora, diría que "nadie puede atribuirse una disposición más amistosa hacia los indios que yo" (Brooks, 2017; Zinn, 2010: 100-114) 
las demandas de la nación lakota de Standing Rock. Según TransCanada, el proyecto del oleoducto Keystone XL tiene el potencial de reducir la cantidad de petróleo que Estados Unidos importa hasta en 40\%, y hay quienes opinan que, para 2020, Estados Unidos podría convertirse en exportador petrolero. Estas afirmaciones adquieren sentido cuando se da a conocer a fines de mayo que Trump retira a su país del Acuerdo de París sobre el Cambio Climático porque no cree que dicho cambio se deba a la actividad humana, posición contraria a la avalada por 195 países que toman en serio el impacto del efecto invernadero. La decisión, calificada al menos como "decepcionante" por la onU y por algunos gobernantes, no augura una resolución favorable a las demandas de parar la construcción de oleoductos que afectan o ponen en riesgo el entorno de indígenas y no indígenas, en particular a los habitantes de Standing Rock.

Lo que podría esperarse es que movimientos como NoDAPL mantengan la vigencia de las demandas por el territorio, la lucha por el reconocimiento de una identidad india que aprecia de manera singular su relación con el entorno y la exigencia de respeto a la tierra y el cuidado de los "parientes" (acuíferos, forestales, minerales) que nos permitan subsistir como humanidad. Vemos también cómo la identificación y solidaridad con los movimientos indios adquieren otra dimensión en un mundo globalizado y hacen posible un mayor contacto e identificación. Quizás estas alianzas marquen el inicio de un panneoindianismo que exprese la organización entre pueblos originarios, la articulación de sus demandas y nuevos y creativos canales para lograrlas.

\section{Figura 4 \\ Vista del campamento de Standing Rock}

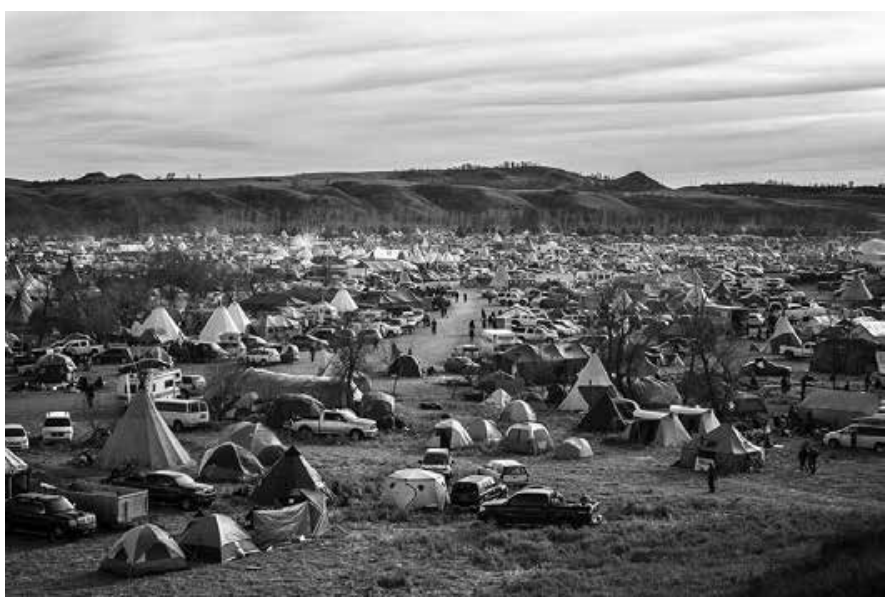

Foto: Rashar Anabtawi <https: / /www.behance.net/ gallery/45721909/The-Prophecy-of-the-Black-Snake>.

\section{Fuentes}

ARGENTINA INDYMEDIA

2016 "EE.UU. vive su mayor reunión indígena desde 1876", en Argentina Indymedia, 23 de septiembre <http: / / argentina.indymedia.org/ news/2016/09/897210.php> [15 de febrero de 2017].

Belle, Nicholas Ivan

2004 "Dancing towards Pan-Indianism: The Development of the Grass Dance and Northern Traditional Dance in Native American Culture", Electronic Theses, Treatises and Dissertations, The Graduate School, núm. 1309, Florida State University Libraries <https: / / fsu digital.flvc.org/islandora/object/fsu: 175850/ datastream/PDF/view $>$ [ 13 de febrero de 2015]

BRAINe, Theresa

2016 "Archaeological Experts Appalled at DAPL Sacred Site Destruction: 1281 Sign Petition", en Indian Country Today, 23 de septiembre <http: / / indiancountrytodaymedianetwork. com / 2016/09/23/archaeological-expertsappalled-dapl-sacred-site-destruction-1281 sign-petition-165877> [ 13 de febrero de 2017].

BRoOKS, DAVID

2017 "Cruel e inusual", en La Jornada, lunes 20 de marzo, p. 25.

Descola, Philippe y Gísli Palsson (coords.)

2001 Naturaleza y sociedad. Perspectivas antropológicas, Siglo xxi Editores, México.

EARTH FIRST! NEWSWIRE

2016 "First Nations and Tribes Sign New Treaty Joining Forces to Stop All Tar Sands Pipelines", en Earth First! Newswire, 23 de septiembre <http://earthfirstjournal.org/ newswire / 2016/09/23/first-nations-andtribes-sign-new-treaty-joining-forces-to-stopall-tar-sands-pipelines/> [14 de febrero de 2017].

Enciso, ANGÉlicA

2017 "Indios siux denuncian premura para desalojar tierras en riesgo de inundación”, en La Jornada, martes 21 de febrero, p. 33.

Escobar, Arturo

1999 Elfinal del salvaje. Naturaleza, cultura y política en la antropología contemporánea, Instituto Colombiano de Antropología / Centro de Estudios de la Realidad Colombiana, Santafé de Bogotá.

Escobar, Arturo

2014 Sentipensar con la tierra. Nuevas lecturas sobre desarrollo, territorio y diferencia, Ediciones Unaula, Medellín.

Estes, NiCK

2016 "Fighting for Our Lives: \#NoDAPL in Historical Context", en The Red Nation, 16 de septiembre <https: / / therednation.org/2016/09/18/ fighting-for-our-lives-nodapl-in-context/> [ 17 de enero de 2017].

Getches, David H.

2002 "Los derechos e intereses relacionados con el agua de los pueblos indígenas bajo la ley estadounidense", en Seminario Internacional Legislación de Aguas y Derechos Indígenas WALIR, Wageningen, pp. 17-32<http:/ www cepal.org/drni/proyectos/walir/doc/walir2 pdf> [14 de febrero de 2017]. 
HANSON, JEFFERY R.

1997 "Ethnicity and the Looking Glass: The Dialectics of National Indian Identity", en American Indian Quarterly, vol. 21, núm. 2, primavera, pp. 195208 <http: / / www.jstor.org/stable/ 1185644 > [ 19 de noviembre de 2014].

Hawkins, DereK

2016 "Police Defend Use of Water Cannons on Dakota Access Protesters in Freezing Weather", en The Washington Post, 21 de noviembre <https: / /www.washingtonpost.com/news / morning-mix/wp/2016/11/21/police-citingongoing-riot-use-water-cannons-on-dakotaaccess-protesters-in-freezing-weather/?utm term=.c32d6f363e95> [5 de diciembre de 2016].

Heppler, Jason A.

2009 "Framing Red Power: The American Indian Movement, the Trail of Broken Treaties, and the Politics of Media”, en DigitalCommons@University of Nebraska - Lincoln, núm. $21<$ http:// digitalcommons.unl.edu/historydiss / 21> [25 de enero de 2012].

Hertzberg, Hazel W.

1981 The Search for an American Indian Identity. Modern Pan-Indian Movements, Syracuse University Press, Syracuse.

THE INDEPENDENT / UK

2016 "US Veterans Return to Standing Rock to Form Human Shield to Protect Dakota Access Pipeline Protesters", en The Independent/UK, diciembre <http://www.independent.co.uk/ news/world/americas/us-politics / us-armyveterans-human-shield-dakota-accesspipeline-standing-rock-a7576291.html> [febrero de 2017].

\section{LA JORNADA}

2017 "Autoriza Estados Unidos la construcción del oleoducto binacional Keystone XL", en $L a$ Jornada, 25 de marzo, p. 25.

Llaven AnZures, Yadira

2016 "Gasoducto Tuxpan pone en riesgo 130 comunidades de la Sierra Norte: Consejo Xängü Yamui", en La Jornada de Oriente, 15 de septiembre <http: / /www.lajornadadeoriente.com. $\mathrm{mx} / 2016 / 09 / 15 /$ gasoducto-tuxpan/> [10 de septiembre de 2016].

MCBRIDE, JESSICA

2017 "Trump Dakota Access Pipeline Executive Order: 5 Fast Facts You Need to Know", en Heavy - News, 24 de enero <http://heavy. $\mathrm{com} /$ news / 2017/01/trump-dakota-accesspipeline-executive-order-dapl-standing-rockno-keystone-investment-energy-transferpartners-kelcy-warren-donation/> [10 de marzo de 2017].

Native Daily Network

2016 "Standing Rock at the United Nations", en YouTube, 20 de septiembre <https://www. youtube.com/watch?v=h1 mr5ojEQYO $>$ [ $13 \mathrm{de}$ febrero de 2017].

ORTEGA, José

1992 "Los Indios: Apartheid Made in the U.S.A.", en La Palabra y el Hombre, núm. 82, abril-junio, pp. 21-44.
Protect Mother Earth

2016 "Standing Rock: Thousands of Wild Buffalo Appear Out of Nowhere", en YouTube, 29 de octubre <https://www.youtube.com/ watch?v=fetubOFvEwk> [ 15 de febrero de 2017]

Rios, Kelly

2008 "The Efficacy of the Red Power Movement", en Perspectives: A Journal of Historical Inquiry, pp. 43-54 <http: / / www.calstatela.edu/sites / default/files / groups / Perspectives/Vol35/rios. pdf $>$ [ 13 de febrero de 2017].

Sacred Stone Camp

2016 "Sacred Stone Camp", en Facebook, 5 de septiembre <https://www.facebook.com/ CampOfTheSacredStone/photos/a.1696414 397314258.1073741828.1570124769943222 / $1766681106954253 /$ ?type $=3>$ [ 17 de enero de 2017].

Simon, Evan y Janet Weinsten

2017 "Standing Rock Fight Comes to Washington for Multuday Protest", en $A B C$ News, 7 de marzo <http: / /abcnews.go.com/US/standingrock-fight-washington-multi-day-protest / story?id=45964806 > [ 10 de marzo de 2017].

Thomas, Robert K.

1965 "Pan-Indianism", en Midcontinent American Studies Journal, vol. 6, núm. 2, otoño, pp. 7583 <http: / /www.jstor.org/ stable / 40640557> [22 de febrero de 2015].

TOlan, SANDY

2016 "How a Fight against the 'Black Snake' at Standing Rock Formed a Global Community", en Los Angeles Times, 14 de noviembre <http: / / www.latimes.com/nation/la-na-showdown-atstanding-rock-20161108-story.html> [22 de diciembre de 2016].

TUPPER, JENNIFER

2014 "Social Media and the Idle No More Movement: Citizenship Activism and Dissent in Canada", en Journal of Social Science Education, vol. 3, núm. 4, invierno, pp. 87-94 <https://www. academia.edu/10352274/Social_Media_and_ the_Idle_No_More_Movement_Citizenship_ Activism_and_Dissent_in_Canada> [14 de febrero de 2017].

WILSON, RAYMOND

1999 Ohiyesa. Charles Eastman, Santee Sioux, University of Illinois Press, Chicago.

Wong, Julia Carrie

2017 "Police Remove Last Standing Rock Protesters in Military-style Takeover", en The Guardian, jueves 23 de febrero <https://www. theguardian.com/us-news / 2017 / feb / 23 / dakota-access-pipeline-camp-cleared-stand-

WOOLF, NiCKY ing-rock> [ 14 de febrero de 2017]

2016 "North Dakota Oil Pipeline Protesters Stand their Ground: 'This is Sacred Land", en The Guardian, martes 29 de agosto <https: / / www. theguardian.com/us-news / 2016/aug/29/ north-dakota-oil-pipeline-protest-standingrock-sioux> [15 de febrero de 2017].

ZINN, HOWARD

2010 La otra historia de los Estados Unidos (desde 1492 hasta hoy), Siglo xxi Editores, México. 